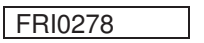

OFF-LABEL USE OF BIOLOGICAL THERAPIES IN RELAPSING AND/OR REFRACTORY EOSINOPHILIC GRANULOMATOSIS WITH POLYANGIITIS (CHURGSTRAUSS)

Alice Canziann ${ }^{1}$, Nils Venhoff ${ }^{2}$, Silvia Sartorelli ${ }^{3}$, Anne Marie Ruppert ${ }^{4}$ Matthieu Groh ${ }^{5}$, Camille Taille ${ }^{6}$, Virginie Rieu ${ }^{7}$, Perrine Smets ${ }^{7}$, Francois Maurier ${ }^{8}$, Nicolas Girszyn ${ }^{9}$, Maxime Samson ${ }^{10}$, Claire De Moreuil ${ }^{11}$, Gregory Pugnet ${ }^{12}$, Xavier Delbrel ${ }^{13}$, Jean-Emmanuel Kahn ${ }^{5}$, Xavier Puéchal ${ }^{14}$, Giacomo Emmi ${ }^{15}$, Loïc Guillevin ${ }^{16}$, Lorenzo Dagna ${ }^{3}$, Jens Thiel ${ }^{17}$, Augusto Vaglio ${ }^{1}$, Benjamin Terrier ${ }^{18} .{ }^{1}$ University of Parma, Parma, Italy, ${ }^{2}$ University of Frieburg, Frieburg, Germany; ${ }^{3}$ IRCCS San Raffaele Hospital, Milan, Italy, ${ }^{4}$ Hopital Tenon, Paris, France; ${ }^{5} \mathrm{Hopital}$ Foch, Paris, France; ${ }^{6} \mathrm{Hopital}$ Bichat, Paris, France; ${ }^{7} \mathrm{CHU}$ de Clermont-Ferrand, Clermont-Ferrand, France; ${ }^{8}$ Metz Private Hospital, Metz, France; ${ }^{9} \mathrm{CHU}$ de Rouen, Rouen, France; ${ }^{10}$ Dijon, Dijon, France; ${ }^{11} \mathrm{CHU}$ de Brest, Brest, France; ${ }^{12} \mathrm{CHU}$ de Toulouse, Toulouse, France; ${ }^{13} \mathrm{CH}$ de Pau, Pau, France; ${ }^{14}$ Cochin Hospital, Paris, France; ${ }^{15}$ University of Florence, Florence, Italy, ${ }^{16}$ Université Paris Descartes, Paris, France; ${ }^{17}$ University of Frieburg, Frieburg, France; ${ }^{18}$ Paris Descartes University, Paris, France

Background: Eosinophilic granulomatosis with polyangiitis (EGPA), formerly named Churg-Strauss syndrome, is a small-vessel necrotizing vasculitis associated with eosinophilia and asthma. Glucocorticoids (GCs) usually control the disease, but relapses and GC-dependant asthma are frequent, leading to potential biological therapy use.

Objectives: We examined off-label biological therapy use for relapsing/ refractory EGPA.

Methods: Remission was defined as the absence of asthma and vasculitis manifestations with a prednisone dose $\leq 5 \mathrm{mg} /$ day, and partial response as the absence of manifestations requiring prednisone dose between 6 and $10 \mathrm{mg} /$ day.

Results: One hundred and eigteen patients (66 men, 52 women; median age 50.5 years) were included. Fifty (42\%) patients received rituximab (RTX), 38 (32\%) mepolizumab (MEPO), and 30 (26\%) omalizumab (OMA).

Previous treatments were: oral GCs (98\%), methylprednisolone infusions $(51 \%)$, azathioprine $(68 \%)$, cyclophosphamide $(47 \%)$, methotrexate $(30 \%)$, mycophenolate mofetil (8\%).

At inclusion, median (interquartile range) BVAS in the RTX, OMA and MEPO groups were 8 (4.5-13), 2 (1.5-4) and 2 (2-5), respectively, median (IQR) daily GCs dose were $20 \mathrm{mg} /$ day (15-40), $20 \mathrm{mg} /$ day (10$37.5), 10 \mathrm{mg} /$ day $(7.5-20)$. GC-dependant asthma was found in $39(78 \%)$ of the RTX group, $36(95 \%)$ in the MEPO group and $28(93 \%)$ in the OMA group.

After median follow-up of 22.8 months (IQR 10-47), remissions, partial responses and therapeutic failures, respectively, were noted in $50 \%, 16 \%$ and $34 \%$ for RTX recipients, $17 \%, 38 \%$ and $45 \%$ for the OMA group and $84 \%, 3 \%$ and $13 \%$ for the MEPO group.

Median BVAS dropped to 0 at 6 and 12 months and at last follow-up in all groups. A GC-sparing effect seemed more important with RTX and MEPO. Median GCs dose decreased from the baseline $20 \mathrm{mg} /$ day to 8.5 at 6 months, 7.5 at 12 months and 5 at last follow-up in the RTX group, from $20 \mathrm{mg} /$ day to 12 at 6 months, 10 at 12 months and 10 at last follow-up in the OMA group, and from $10 \mathrm{mg} /$ day to 5 at 6 months, 3 at 12 months and 5 at last follow-up in the MEPO group. In the MEPO group, no difference was noted between patients receiving 100 $\mathrm{mg}$ and those $300 \mathrm{mg}$ monthly.Nine (18\%) patients stopped RTX because of refractory disease, and $12(24 \%)$ experienced adverse events, including severe infections in 5 . Thirteen (43\%) stopped OMA because of severe infusion reaction in one and refractory disease in 12 , and 4 $(13 \%)$ patients receiving OMA experienced adverse events. Three $(8 \%)$ patients stopped MEPO because of adverse events in 2 (one severe infusion reaction and one because of paresthesia), because of pregnancy in one. Seven (18\%) additional patients receiving MEPO experienced adverse events, mainly asthenia.

Conclusion: The results suggest that RTX may be effective in $50 \%$ of patients with vasculitis relapses related to EGPA, with an acceptable safety profile, while MEPO is highly effective with a good GCs-sparing effect and safety profile in patients with steroid-dependant asthma.

Disclosure of Interests: Alice Canzian: None declared, Nils Venhoff: None declared, Silvia Sartorelli: None declared, Anne Marie Ruppert: None declared, Matthieu Groh: None declared, Camille Taille: None declared, Virginie Rieu: None declared, Perrine Smets: None declared, Francois Maurier: None declared, Nicolas Girszyn: None declared, Maxime Samson: None declared, Claire De Moreuil: None declared, Gregory Pugnet: None declared, Xavier Delbrel: None declared, Jean-Emmanuel Kahn: None declared, Xavier Puéchal: None declared, Giacomo Emmi: None declared, Loïc Guillevin: None declared, Lorenzo Dagna Consultant for: Prof Lorenzo Dagna received consultation honoraria from Abbvie, Amgen,
Biogen, Bristol-Myers Squibb, Celltrion, Novartis, Pfizer, Sanofi-Genzyme, and SOBI., Jens Thiel: None declared, Augusto Vaglio: None declared, Benjamin Terrier: None declared

DOI: 10.1136/annrheumdis-2019-eular.6243

\section{FRI0279 MYCOPHENOLATE MOFETIL IN THE TREATMENT OF MAJOR ORGAN INVOLVEMENT OF PATIENTS WITH BEHÇET'S SYNDROME}

Sinem Nihal Esatoglu ${ }^{1}$, Emir Cemre ${ }^{2}$, Vedat Hamuryudan ${ }^{1}$, Yilmaz Ozyazgan ${ }^{3}$, Didar Ucar ${ }^{3}$, Zekayi Kutlubay ${ }^{4}$, Serdal Ugurlu ${ }^{1}$, Emire Seyahi ${ }^{1}$, Melike Melikoglu ${ }^{1}$ Izzet Fresko', Sebahattin Yurdakul ${ }^{1}$, Hasan Yazici ${ }^{1}$, Gulen Hatemi ${ }^{1} .{ }^{1}$ stanbul University-Cerrahpasa, Cerrahpasa Medical Faculty, Department of Internal Medicine, Division of Rheumatology, Istanbul, Turkey; ${ }^{2}$ Istanbul UniversityCerrahpasa, Cerrahpasa Medical Faculty, Department of Internal Medicine Istanbul, Turkey, ${ }^{3}$ Istanbul University-Cerrahpasa, Cerrahpasa Medical Faculty, Department of Ophthalmology, Istanbul, Turkey, ${ }^{4}$ Istanbul University-Cerrahpasa, Cerrahpasa Medical Faculty, Department of Dermatology, Istanbul, Turkey

Background: Mycophenolate mofetil (MMF) has been increasingly used in various rheumatic diseases. It may also be a safe and effective treatment option for Behçet's syndrome (BS) where oral immunosuppressives other than azathioprine and cyclosporine are not available.

Objectives: We aimed to report our experience with MMF in BS patients with major organ involvement.

Methods: We retrospectively reviewed the charts of all BS patients who started using MMF between 2016 and 2018. Demographic characteristics, MMF indication, history of previous immunosuppressive agents, concomitant therapies with MMF, adverse events and outcome were recorded from the chart review.

Results: We evaluated 39 BS patients (M/W: 30/9, mean age: $39 \pm 8$ years) treated with MMF during a mean follow-up of $18 \pm 13$ months. Of 39 patients, 31 received MMF for maintenance of remission therapy, while 8 had active disease at the initiation of MMF. The main indications were vascular involvement in 26 , eye involvement in 11 , and neurologic involvement in 2 patients. Among the 26 patients with vascular involvement, 13 had deep vein thrombosis, 6 had pulmonary artery involvement, and 3 had arterial involvement.

Twenty-nine patients started MMF after azathioprine due to adverse events such as leucopenia, gastrointestinal intolerance and elevation of liver enzymes. MMF was chosen in 2 patients because of concomitant use of warfarin, that may be problematic with azathioprine. The remaining 8 patients were treated with MMF due to active disease despite azathioprine.

In 20/39 (50\%) patients MMF was used concomitantly with biologics (infliximab in 15 and adalimumab in 5). One patient additionally used cyclosporine-A and 7 patients used low-dose prednisolone.

At the end of follow-up, 33 of the patients were still using MMF. The reasons for MMF discontinuation were recurrent superficial thrombophlebitis in 3 patients with previous lower extremity deep vein thrombosis, fear from adverse events, desire of pregnancy and itching in 1 patient each There were no serious adverse events or adverse events leading to discontinuation except for itching. None of the patients experienced exacerbation of mucocutaneous lesions during MMF treatment.

Conclusion: MMF seems to be a safe and effective alternative especially when used for maintenance of remission or in addition to biologic agents in active patients with major organ involvement.

Disclosure of Interests: Sinem Nihal Esatoglu: None declared, Emir Cemre: None declared, Vedat Hamuryudan Consultant for: Abbvie, Amgen, BMS, Jansen, MSD, Pfizer, UCB, Speakers bureau: Abbvie, Amgen, BMS, Jansen, MSD, Pfizer, UCB, Yilmaz Ozyazgan Speakers bureau: ABBVIE, Didar Ucar: None declared, Zekayi Kutlubay: None declared, Serdal Ugurlu: None declared, Emire Seyahi: None declared, Melike Melikoglu: None declared, Izzet Fresko: None declared, Sebahattin Yurdakul: None declared, Hasan Yazici: None declared, Gulen Hatemi Consultant for: Abbvie, Amgen, BMS, Janssen, MSD, Pfizer, UCB, Speakers bureau: Abbvie, Amgen, BMS, Jansen, MSD, Pfizer, UCB, DOI: 10.1136/annrheumdis-2019-eular.4309 